\title{
The role of CD44 in epithelial-mesenchymal transition and cancer development
}

This article was published in the following Dove Press journal:

OncoTargets and Therapy

16 December 2015

Number of times this article has been viewed

\author{
Hanxiao Xu' \\ Yijun Tian' \\ Xun Yuan' \\ Hua $\mathrm{Wu}^{\prime}$ \\ Qian Liu' \\ Richard G Pestell ${ }^{2}$ \\ Kongming $\mathrm{Wu}^{\prime}$
}

'Department of Oncology, Tongji Hospital, Tongji Medical College, Huazhong University of Science and Technology, Wuhan, People's Republic of China; ${ }^{2}$ Sidney Kimmel Cancer Center, Thomas Jefferson University, Philadelphia, PA, USA
Correspondence: Kongming Wu Department of Oncology, Tongji Hospital, Tongji Medical College, Huazhong University of Science and Technology, 1095 Jiefang Avenue, Wuhan 430030, People's Republic of China Email kmwu@tjh.tjmu.edu.cn

\begin{abstract}
CD44, a multi-structural and multifunctional transmembrane glycoprotein, was initially identified as a receptor for hyaluronan that participates in both physiological and pathological processes. CD44 is found to be closely linked to the development of various solid tumors. Molecular studies have revealed that high CD44 expression was correlated with the phenotypes of cancer stem cells and epithelial-mesenchymal transition, thereby contributing to tumor invasion, metastasis, recurrence, and chemoresistance. Correspondingly, blockade of CD44 has been demonstrated to be capable of attenuating the malignant phenotype, slowing cancer progression, and reversing therapy resistance. Clinical analyses showed that high CD44 expression is associated with poor survival of various cancer patients, indicating that CD44 can be a potential prognostic marker. In this review, we summarize recent research progress of CD44 on tumor biology and the clinical significance of CD44.
\end{abstract}

Keywords: CD44, epithelial-mesenchymal transition, tumor progression, prognosis

\section{Introduction}

CD44, a complex transmembrane glycoprotein, also called Hermes antigen, homing cell adhesion molecule, HUTCH-1, phagocytic glycoprotein-1, lymphocyte-homing receptor, and ECM-III, is encoded by the CD44 gene on chromosome $11,{ }^{1}$ which consists of 20 exons. ${ }^{2}$ Transcripts for the CD44 gene undergo complex alternative splicing, which results in many functionally distinct isoforms, such as CD44 standard isoform (CD44s) and CD44 variant isoform (CD44v). ${ }^{3}$ The smallest CD44s is encoded by constant exons 1-5 and 16-20 and translated into a polypeptide of a molecular mass of $80-85 \mathrm{kDa}$ (Figure 1). Exon 1 is an N-terminal signal sequence, exons 2 and 3 are a link module that binds to hyaluronic acid (HA), exons 4, 5, 16, and 17 compose a stem region, exon 18 makes up a single-pass transmembrane domain, and exon 20 forms a cytoplasmic domain. ${ }^{4}$ Exon 19 is spliced out in all forms of CD44 cDNAs. ${ }^{4}$ Alternative splicing is the basis not only for the structural but also for functional diversity of this protein. Multiple CD44v is produced by insertion of variant exons (v1-v10) at the proximal plasma membrane external region (Figure 1). ${ }^{4} \mathrm{CD} 44 \mathrm{~s}$ is found in most cells, ${ }^{5}$ while CD44v is expressed primarily on cells during inflammation and on tumor cells. ${ }^{6-8}$ CD44 protein consists of a short C-terminal cytoplasmic domain, a transmembrane domain, and seven extracellular domains which contains an N-terminal HA-binding link-homology module and stem region (Figure 2). ${ }^{9,10}$

CD44 was initially identified as a receptor for HA and lymphocyte-homing receptor $^{11}$ that participates in both physiological and pathological processes, including cell adhesion, angiogenesis, inflammation, and tumor development. ${ }^{12,13}$ Since CD44 expression in several tumor types was found to be different from that in normal counterparts, studies have been subsequently carried out to investigate the role of 


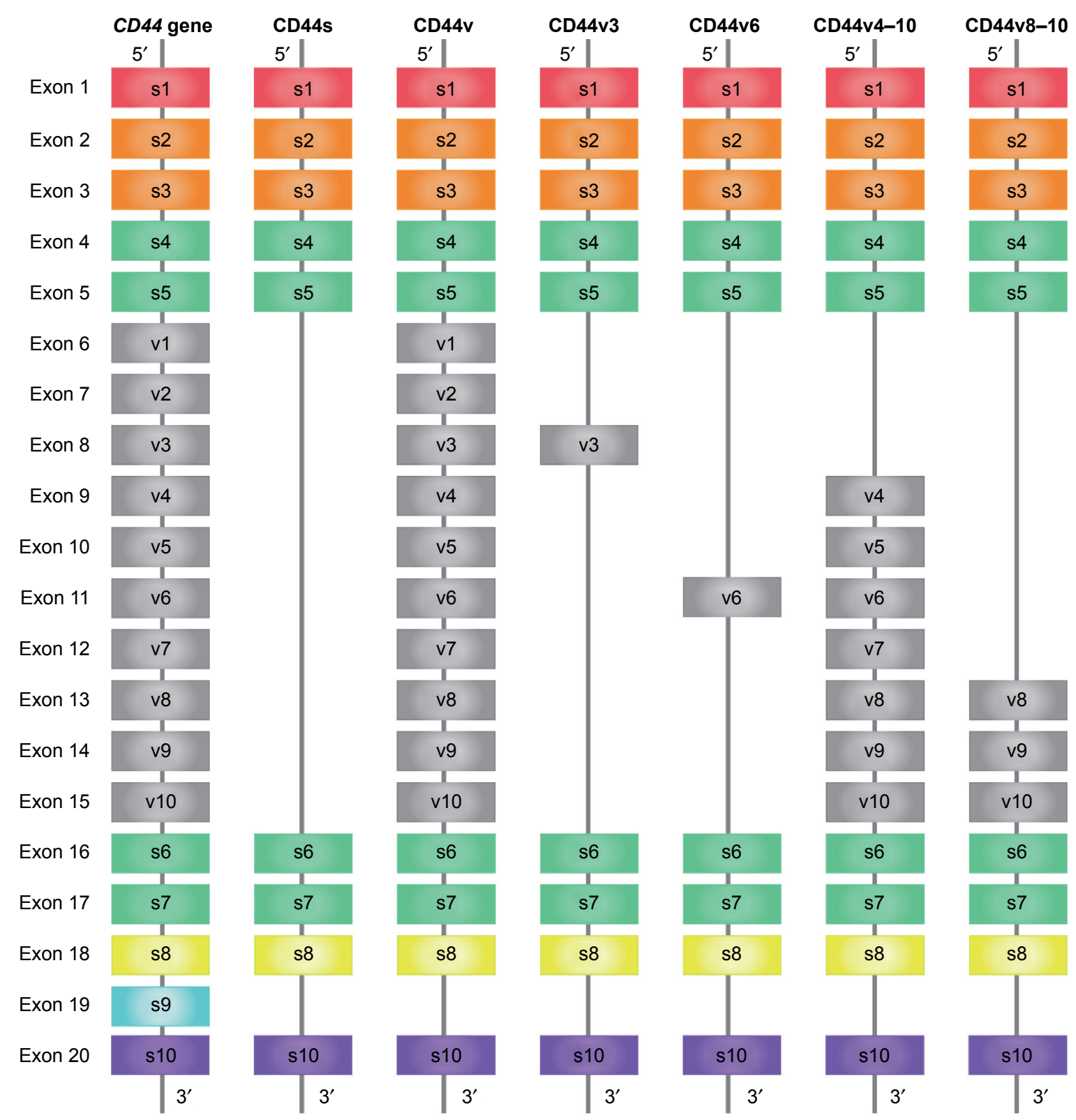

Figure I Schematic structures of alternative splicing in CD44.

Notes: CD44 gene contains 20 exons. ${ }^{10}$ Alternative splicing gives rise to CD44s and CD44v. Exon I is an $\mathrm{N}$-terminal signal sequence, exons 2 and 3 are a link module that binds to $\mathrm{HA}$, exons 4, 5, 16, and 17 compose a stem region, exon 18 makes up a single-pass transmembrane domain, and exon 20 forms a cytoplasmic domain. ${ }^{10}$ Exon 19 is spliced out in all forms of CD44 cDNAs. ${ }^{4}$ The smallest CD44s is encoded by constant exons I-5 and I6-20. ${ }^{10}$ Multiple CD44v is produced by insertion of variant exons (exons 6-I5), typically identified as vI-v I0. CD44 variant can contain one or more variant regions, such as CD44v3, CD44v6, CD44v4-10, or CD44v8-10. Figure adapted from Chanmee T, Ontong P, Kimata K, Itano N. Key roles of hyaluronan and its CD44 receptor in the stemness and survival of cancer stem cells. Front Oncol. 20I5;5: I80. Available from: http:// journal.frontiersin.org/article/I0.3389/fonc.2015.00180/abstract. Copyright @ 2015 Chanmee, Ontong, Kimata and Itano. ${ }^{10}$

Abbreviations: CD44s, CD44 standard; CD44v, CD44 variant; HA, hyaluronic acid; s, standard; v, variant.

CD44 in cancer development for decades. The expression of CD44 is regulated by many extracellular or intracellular factors. For example, CD44 is a target of the Wnt pathway. ${ }^{14}$ Currently, extensive research reveals that CD44 is critical in epithelial-mesenchymal transition (EMT). CD44 has also been reported to be one of the key biomarkers for isolation and characterization of cancer stem cells (CSCs). Recent studies showed that specific targeted knockdown of CD44 attenuated cancer progression, ${ }^{15,16}$ which suggests that CD44 may be a promising target of cancer treatment. Most studies indicate that high CD44 expression is closely linked to clinical parameters, ${ }^{17-19}$ and a promising prognostic indicator in several solid tumors, including lung cancer ${ }^{20}$ breast cancer, ${ }^{21}$ prostate cancer, ${ }^{22}$ gastric cancer ${ }^{23}$ colon cancer, ${ }^{24}$ malignant glioma, ${ }^{25}$ and ovarian cancer. ${ }^{19}$ In this review, we summarize new insights into the regulation of CD44, the involvement of CD44 in EMT and CSCs, as well as the relevance of CD44 for clinical outcome. 


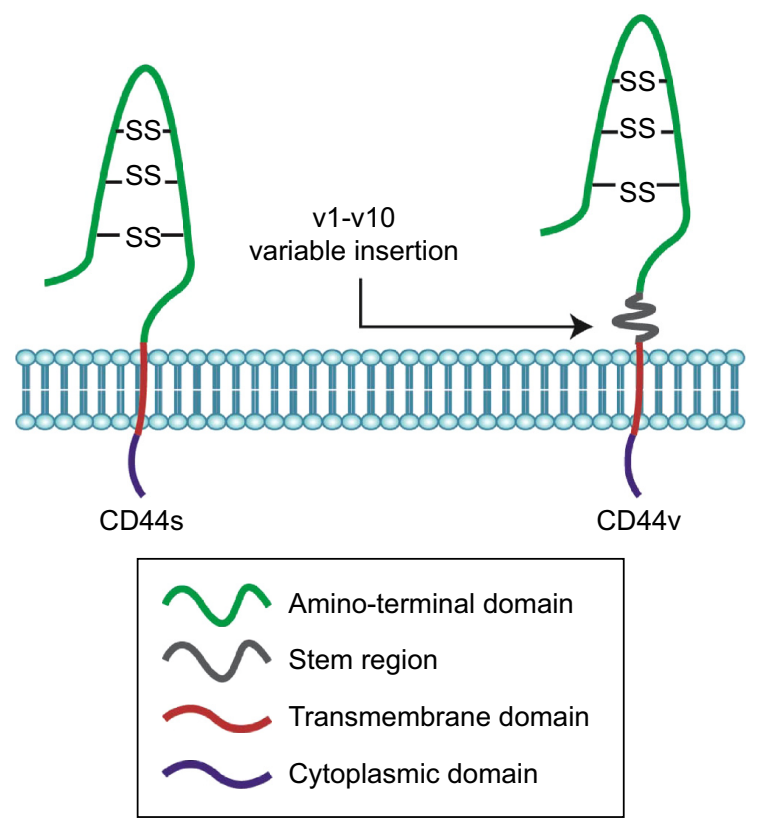

Figure 2 Key domains of CD44.

Notes: CD44 protein consists of a short C-terminal cytoplasmic domain, a transmembrane domain, and seven extracellular domains which contain an $\mathrm{N}$-terminal HA-binding link-homology module and stem region. In CD44v, variant exons are inserted into the stem region at the proximal plasma membrane external region. Figure adapted from Misra S, Hascall VC, Markwald RR, Ghatak S. Interactions between hyaluronan and its receptors (CD44, RHAMM) regulate the activities of inflammation and cancer. Front Immunol. 2015;6:20I. Available from: http://journal.frontiersin.org/article/I0.3389/ fimmu.20I5.0020I/abstract. Copyright: (C) 2015 Misra, Hascall, Markwald and Ghatak. ${ }^{4}$ Abbreviations: $\mathrm{HA}$, hyaluronic acid; CD44s, CD44 standard; CD44v, CD44 variant; SS, disulfide bond; v, variant.

\section{Regulation of CD44 expression}

CD44 expression is regulated by many extracellular or intracellular factors during tumor development. Activation of STAT3 signaling promotes stem cell-like traits by upregulating CD44, and a feedback regulation between STAT3 and CD44 is observed. Interleukin- 6 exposure activated interleukin-6/STAT3 signaling in CD44(-) T47D cells and induced upregulation of $\mathrm{CD} 44$ protein expression, resulting in the enrichment of CD44(+) cell population. ${ }^{18}$ In breast cancer MDA-MB-231 cells, CD44 promoted the phosphorylation of STAT3 by interacting with STAT3, and then the pSTAT3 moved to nucleus and combined with NF- $\mathrm{KB}$ to activate hTERT, which in turn increased CD44 expression (Figure 3). ${ }^{26}$ Shang et al revealed that transforming growth factor $\beta 1$ (TGF- $\beta 1$ ) upregulated CD44 expression in prostate cancer LNCaP and CWR22RV1 cells. ${ }^{22}$ In agreement with these findings, blocking TGF- $\beta 1$ signaling by using SB431542 in these cells decreased CD44 expression. ${ }^{22}$ Similar phenomena were also reported in hepatocellular carcinoma (HCC) and oral cancer. ${ }^{27,28}$

MicroRNA (miRNA) profiling has revealed that several miRNAs are involved in the regulation of CD44 expression in a variety of cancer cells. Song et al have demonstrated that miR-9 promotes $\mathrm{CD} 44$ expression by inducing $\beta$-catenin nuclear translocation. Correspondingly, knocking down miR-9 in esophageal squamous cell carcinoma (SCC) KYSE30 and KYSE510 cells decreased the CD44 protein abundance. ${ }^{29}$ However, some other members of the miRNA family, including miR-34a ${ }^{17}$ and miR-203, ${ }^{30}$ regulate CD44 in an opposite manner. For example, miR-34a negatively correlated with the expression of CD44. ${ }^{17}$ Restoration of miR-34a was capable of decreasing CD44 protein in bladder cancer cells by directly and specifically interacting with the target site in the CD44'-UTR. ${ }^{17}$ However, a specific miRNA-targeting CD44 expression has not been fully identified yet.

There are many other molecules regulating CD44 expression, such as VCAM-1 (CD106), ${ }^{31}$ actin-binding Fascin, ${ }^{32}$ and cyclin-dependent kinase-like $2 .{ }^{33}$ Generally speaking, CD44 expression is regulated by a complicated network through interacting with other pathways to convey its function in many tumor types.

\section{CD44 and EMT}

EMT, a tightly regulated and highly conserved cellular process for a cell type changing from an epithelial phenotype to a mesenchymal phenotype, results in the cell acquiring fibroblast-like properties. It plays a crucial role not only in normal embryogenesis and tissue remodeling but also in the progression of various diseases including inflammation, fibrosis, and especially, in tumor proliferation, invasion, metastasis, recurrence, and drug resistance. ${ }^{34-38}$ EMT is involved in the acquisition of stemness of epithelial tumor cells, which confers cells with aggressive traits and an invasive phenotype that may result in tumor recurrence and metastasis. ${ }^{33,39}$ EMT promotes CD44 expression. Mesenchymal genes, such as TWIST1 ${ }^{34,40} S N A I 1,{ }^{41,42} Z E B 1,{ }^{15,43}$ and $S L U G,{ }^{44}$ are positively correlated with CD44 expression. Li and Zhou revealed that expression of Twist dramatically elevated the level of CD44 in cervical carcinoma HeLa cells and breast cancer MCF-7 cells through activation of $\beta$-catenin and the Akt pathway. ${ }^{34}$ Twist1-induced CD44 expression is also found in head and neck SCC.$^{40}$ Knockdown of ZEB 1 by siRNA reduced CD44 expression in prostate cancer DU-145R and PC-3R cells and prostate tumor samples ${ }^{43}$ Furthermore, overexpression of Slug in $\mathrm{CD} 24^{+} / \mathrm{CD}_{4} 4^{-}$breast cancer MCF-10A and MCF-7 cells gave rise to a subpopulation of $\mathrm{CD} 24^{-} / \mathrm{CD} 44^{+}$cells, and this phenotype conferred enhanced mammosphere forming ability. ${ }^{44}$ In contrast, E-cadherin, an epithelial marker, participates in the negative regulation of CD44 expression. In prostate cancer PC 3 cells, stable knockdown of E-cadherin increased the $\mathrm{CD} 44$ protein abundance. ${ }^{42}$ 


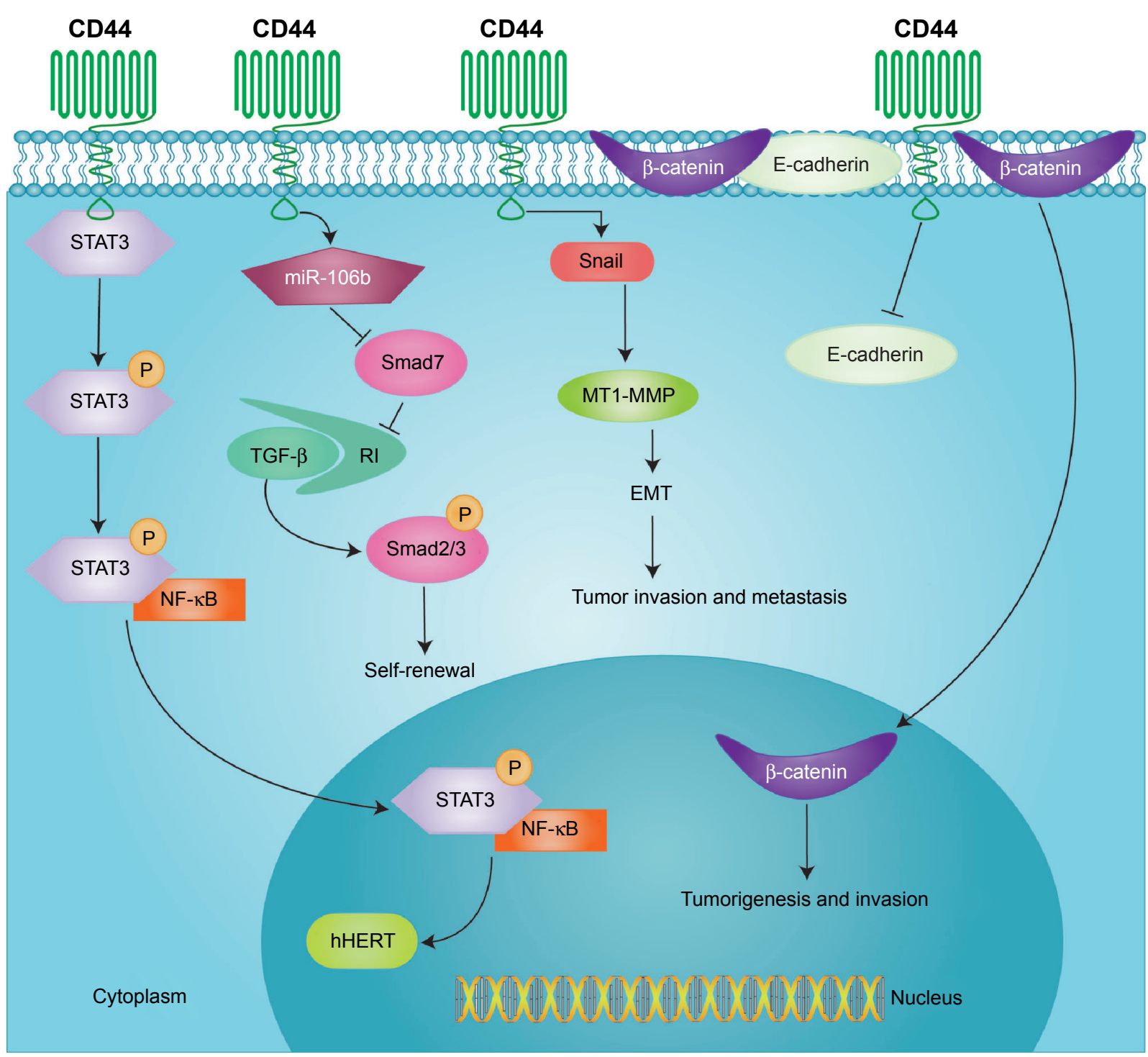

Figure 3 Representative signal pathways induced by CD44.

Notes: CD44 promotes phosphorylation of STAT3, leading to the nuclear translocation of PSTAT3 and activation of hHERT. ${ }^{26} \mathrm{Upregulation}$ of miR-I06b family by CD44 represses inhibitory Smad7, which inhibits TGF- $\beta /$ Smad2/3 signaling by suppressing TGF- $\beta$ receptor I (RI) and then enhances self-renewal of cancer cells; ${ }^{47}$ Snail I upregulates the expression of membrane type I-matrix metalloproteinase (MTI-MMP), which promotes tumor invasion..$^{50} \mathrm{CD} 44$ disassociates the formation of the membrane-associated E-cadherin- $\beta$-catenin complex, releasing $\beta$-catenin translocates into nucleus and activating genes related to cell invasion and migration. ${ }^{46}$

Abbreviations: TGF- $\beta$, transforming growth factor $\beta$; EMT, epithelial-mesenchymal transition; miR, micro RNA; P, phosphorous status of moleculars; RI, receptor I; MTI-MMP, membrane type I-matrix metalloproteinase.

On the other hand, CD44 also promotes EMT in many cancer types, such as colon cancer, ${ }^{45,46}$ gastric cancer, ${ }^{47}$ pancreatic cancer, ${ }^{48-50}$ prostate cancer, ${ }^{22}$ liver cancer, ${ }^{28}$ and glicoma, ${ }^{51}$ by upregulating mesenchymal markers and downregulating epithelial markers. For example, ectopic CD44 expression in SW480 cells induced the EMT phenotype, while knockdown of CD44 attenuated EMT. CD44 upregulated the expression of EGFR, leading to the activation of PI3K/Akt and expression of glycogen synthase kinase-3-beta. CD44 inhibited the formation of the membrane-associated E-cadherin- $\beta$-catenin complex, which resulted in the nuclear translocation of $\beta$-catenin and transcriptional activation of genes related to cell invasion and migration (Figure 3). ${ }^{46}$ However, a different mechanism was observed in gastric cancer. The miR-106b family, including miR-106b, miR-93, and miR-25, was increased in stem-like cells with CD44(+) phenotype compared with CD44(-) cells. The upregulation of the miR-106b family repressed inhibitory Smad7, resulted in the activation of TGF- $\beta /$ Smad signaling, and enhanced EMT in CD44(+) cells (Figure 3) ${ }^{47}$ In a subset of human PanIN cells which are capable of invading the surrounding stroma, oncogenic K-Ras upregulated ATDC, and then ATDC increased CD44 via activation of $\beta$-catenin signaling, leading to the induction 
of an EMT phenotype characterized by expression of Zeb1 and Snail1. ${ }^{48}$

In addition, different isoforms, including CD44s $\mathrm{s}^{21,52,53}$ and CD44v6, ${ }^{54}$ were reported to determine the regulation of EMT. For example, a switch in CD44 isoform expression from CD44v to CD44s was essential for EMT in breast cancer cells. When nontumorigenic epithelial cell lines were induced to go through EMT with different EMT triggers, isoform transition from CD44v to CD44s was found in all these cells by various approaches. Switch from CD44v to CD44s activated Akt signaling, which activated EMT. ${ }^{21}$ Similarly, a high CD44s expression in HCC was significantly associated with the EMT expression profile. ${ }^{52}$ In addition, CD44v6 expression inversely correlates with E-cadherin expression and positively correlates with Vimentin expression in colon cancer. ${ }^{54}$

CD44 displays a close association with EMT by combination with other molecules such as CD29 ${ }^{55}$ and CD24. ${ }^{56-58}$ CD29 ${ }^{\text {high }} / \mathrm{CD} 44^{\text {high }}$ cells display molecular traits of EMT in oral SCC $.{ }^{55} \mathrm{CD} 24^{+} / \mathrm{CD} 44^{+}$phenotype is also positively correlated with EMT in pancreatic cancer. ${ }^{56}$ In breast cancer cell lines SUM149, HCC1954, and MCF-7, gene-expression profiling revealed that $\mathrm{CD} 24^{-} / \mathrm{CD} 44^{+}$cells were enriched for expression of EMT-associated genes, including Vimentin, Zeb1, Zeb2, $\beta$-catenin, and matrix metalloproteinase- $1 .{ }^{57}$

\section{CD44 in self-renewal and tumorigenesis}

Strong evidence supports that CSC drives tumor initiation and metastasis. ${ }^{59} \mathrm{CD} 44$ is selected as a surrogate marker for CSC in many types of cancers. Previous studies have shown that as few as $100 \mathrm{CD} 44(+)$ colorectal cancer cells isolated from patients were able to develop into a heterogeneous tumor, and that spheroids derived from a single CD44(+) cancer cell could recapitulate the heterogeneous hierarchy of tumor cells. ${ }^{60,61} \mathrm{CD} 44(+)$ colon cancer cell population displayed higher soft agar colony-forming ability and tumorigenicity in vivo, compared with CD44(-) cells. ${ }^{45,62}$ When CD44(+) or CD44(-) breast cancer cells were injected into the mammary fat pads of nonobese diabetic/severe combined immune-deficient (NOD/SCID) mice, significantly enhanced tumorigenic and proliferation potential was observed in CD44+ cell, compared to CD44- cells. ${ }^{18}$ CD44 level was higher in the lower chamber cells which displayed high tumorigenic characteristics, compared with the upper chamber cells and the bulk pancreatic cancer Panc-1 cells. Molecular analysis showed that self-renewal pathway (Notch, hedgehog, and Wnt)-related proteins were upregulated in the lower chamber cells. ${ }^{49}$ High CD44 expression is closely correlated with enhanced spheroid colony formation in bladder cancer ${ }^{15}$ and gastric cancer. ${ }^{47}$

CD44 isoforms were reported to be involved in tumorigenesis. Immunostaining for CD44v6 on formalin-fixed, paraffin-embedded sections of colorectal carcinomas showed that the upregulation of CD44v6 through nuclear $\beta$-catenin activation may contribute to the formation of tumorbudding. ${ }^{63}$ Lau et al showed that ectopical expression of CD44v8-10, not CD44s, is closely linked to enhanced tumor-initiation ability of gastric cancer cells. ${ }^{64} \mathrm{CD} 44 \mathrm{v} 8-10$ could rescue the attenuated tumor-initiating potential caused by silencing of total CD $44 .{ }^{64}$

In addition, CD44 displayed its effect on cancer tumorigenesis by association with other molecules. Sorted CD29 high/ CD44 ${ }^{\text {high }}$ A431 cells showed higher proliferating ability in vitro and in NOD/SCID mice compared with CD29 low/ CD44 ${ }^{\text {low }}$ cells. $.^{55} \mathrm{CD} 24^{-} / \mathrm{CD} 44^{+}$subpopulation displayed enhanced ability of tumorigenesis. ${ }^{34,65-67}$ Using mammary fat pad injection in C57BL/6 SCID, CD24-/CD44+ cells showed much more enhanced ability of forming solid tumor than that of unmanipulated BT-20 cells; these findings indicate that CD24-/CD44+ ${ }^{+}$subpopulation had stronger tumorigenicity. ${ }^{65}$ Therefore, the expression of CD44 plays a key role in selfrenewal and tumorigenesis in certain cell types.

\section{CD44 on adhesion, invasion, and metastasis}

CD44 plays pivotal roles in promoting tumor invasion and metastasis by contributing to adhesion of tumors cells to endothelium and fibronectin-enriched matrices. ${ }^{68} \mathrm{CD} 44 \mathrm{v}$ possesses E-selectin ligand activity; expression of CD44 in both breast and colon cancer cell enhances adhesion to endothelial cell and correlates with metastasis potential. ${ }^{69,70}$ CD44 potentiated the adhesion of basal-like breast cancer cell to endothelium and fibronectin in an alpha5B1-integrindependent manner, while CD44 knockdown attenuated adhesion ability. ${ }^{68}$ Silencing CD44 expression attenuated adhesion to endothelial cells and reduced invasion; however, no effect on cancer cell proliferation was observed. In vivo study demonstrated that elevated CD44 expression enhanced post-intravasation events and distant metastasis in mouse model. ${ }^{71}$ In glioblastoma multiforme, a highly invasive brain tumor, decreased CD44 expression reduced cell adhesion to HA, and CD44/HA association contributed to the mechanosensing and invasive ability. ${ }^{72}$ The low-density LRP-1 regulates the adhesion and deadhesion balance in cancer cell. LRP-1-mediated internalization of CD44 
determines the adhesive function of cancer cell. ${ }^{73}$ Besides, tumor suppressor gene FOXP3 repressed CD44 protein expressions to suppress adhesion, resulting in reduced invasion and metastasis of human breast cancer cells. ${ }^{74}$ Recent study showed that aggressive cancer cell acquired the ability to transdifferentiate into endothelial features and form vasculogenic networks. CD44/c-Met signaling plays a critical role in this plasticity. ${ }^{75}$

Increasing evidence indicates that $\mathrm{CD} 44$ promotes tumor invasion and metastasis in multiple cancer types, including bladder cancer, ${ }^{17}$ breast cancer, ${ }^{76-79}$ prostate cancer, ${ }^{80}$ pancreatic cancer, ${ }^{48,50}$ and ovarian cancer. ${ }^{81}$ Cho et al found that CD44 expression was positively correlated with the invasion and metastasis ability of colon cancer SW480 cells. ${ }^{46}$ CD44 overexpression conferred cells with increased cell invasion, whereas knockdown of $C D 44$ by shRNA attenuated cell invasion in 24 hours after cell plating, ${ }^{46}$ as evaluated by matrigel invasion assay. The mechanism involved in the regulation of migration and invasion in colon cancer cells may depend on the inhibition of the association of the membrane-located E-cadherin and $\beta$-catenin by CD $44 .{ }^{46}$ Silencing of $C D 44$ in human bladder cancer 5637 and T24 cells inhibited angiogenesis, migration, and invasion of these cells. ${ }^{17} \mathrm{CD} 44$ upregulation and nuclear $\beta$-catenin conveyed the enhanced invasion ability of MCF-7-14 breast cancer cells and their invasive clone CL6 cells. CD44 also promotes invasion and metastasis of breast cancer cells by modulating c-Src transcription ${ }^{78}$ or upregulating serine protease and collagen-degrading enzymatic expression and activity ${ }^{79}$ Klarmann et al found that only the DU145 and LNCaP cells with CD44(+) phenotype demonstrated invasive activity on matrigel, while CD44(+) and CD44(-) cells showed equal migration across the control membrane in response to serum. ${ }^{80}$ Gao et al found that the level of CD44 is much higher in synchronous metastasis than primary ovarian cancer tissue, and downregulation of CD44 inhibited the migration and invasion capabilities of ovarian cancer cells (SKOV-3TR and OVCAR8TR cells). ${ }^{81}$

CD44 isoforms also affect invasive function in several tumor types. In liver cancer, high expression of CD44s was significantly and positively correlated with HCC invasive macroscopic appearance, intrahepatic dissemination, and frequent vascular invasion..$^{52}$ The knockdown of CD44v6 in human colon carcinoma LoVo and HCT116 cells decreased function with HGF-induced cell migration. ${ }^{54}$

CD44 is also combined with some other molecules to promote invasion and metastasis. MCF-7-14 cells, which had enhanced migratory and invasive ability compared with MCF-7 cells, displayed increased CD44 expression and decreased CD24 expression compared with MCF-7 cells. ${ }^{16}$ CD44-podoplanin interaction promotes directional migration in SCC cells and plays a role in driving tumor cell migration during malignancy. ${ }^{82}$

\section{CD44 and cancer therapy}

CD44 expression correlates with resistance to chemotherapy and radiotherapy. Many reports support that functional inhibition of CD44 at gene or protein level reverses some malignant behaviors and sensitizes to therapy. For example, knockdown of CD44 in liver tumor HLE cells sensitized these cells to sorafenib-induced cell death, accompanied with decreased levels of anti-apoptotic proteins (MCL-1 and Survivin). Further analysis demonstrated that this effect depended on TGF- $\beta$ signaling. ${ }^{28} \mathrm{CD} 44$ level was also found to be higher in the lower chamber cells which display significantly more gemcitabine resistance ability, compared with the upper chamber cells and the bulk Panc-1 cells. ${ }^{49}$ CD44 also accounts for resistance to doxorubicin in patients with breast cancer ${ }^{18}$ and to sunitinib in clear cell renal cell carcinomas. ${ }^{83}$ Gao et al found that only paclitaxel-resistant ovarian cancer cells SKOV-3TR and OVCAR8TR exhibited strong expression of $\mathrm{CD} 44$, while the paclitaxel-sensitive ovarian cancer cells (SKOV-3 and OVCAR8) exhibit normal level of CD44 expression. ${ }^{81}$

In addition, it was found that the subset of CSCs with $\mathrm{CD} 44^{\text {high }} / \mathrm{CD} 24^{\text {low }}$ cell-surface antigen was more resistant to cancer chemotherapy, radiotherapy, and endocrine therapy than the major population of cancer cells which were more differentiated in human breast tumors. ${ }^{84}$ Therefore, CD44 may be a potential target for cancer treatment. Recent studies showed that CD44 knockdown suppressed spheroid colony formation and attenuated cancer progression in bladder cancer T24-L cells (lung-metastatic T24) ${ }^{15}$ Besides, CD44 isoforms are also capable of modifying therapeutic effects. ${ }^{85}$ Knockdown of CD44v6 in multiple prostate cancer cell lines reduced sphere formation, inhibited invasive abilities, and enhanced chemo-/radiosensitivity. Molecular analyses revealed the downregulation of PI3K/Akt/mTOR and Wnt/ $\beta$-catenin signaling pathway. ${ }^{86}$

Anti-CD44 mAb significantly inhibited cell migration and invasion of breast cancer MCF-7 cells by inducing CD44 degradation from the cell surface, ${ }^{16}$ indicating that CD44 may be a novel molecular target. Also, it was found that CD44 was a crucial regulator of acute myeloid leukemia stem cells, and antibody to CD44 could dramatically reduce leukemic repopulation in NOD/SCID mice transplanted with human acute myeloid leukemia. ${ }^{87}$ 


\section{Clinical significance of CD44}

Accumulating evidence demonstrates that CD44 is closely linked to clinical features of various cancer types, including prostate cancer, ${ }^{22}$ gastric cancer, ${ }^{23}$ malignant glioma, ${ }^{25}$ colon cancer, ${ }^{54}$ kidney cancer ${ }^{83}$ and breast cancer. ${ }^{16,88}$ Correlation analyses of CD44 expression in prostate cancer tissues indicated that the high CD44 expression was significantly associated with biochemical recurrence and distant metastasis. Thus, CD44 may be a poor prognostic marker of prostate cancer. ${ }^{22}$ High expressions of CSC marker CD44 in gastric cancer patients with curative resection were prominent in early recurrence. ${ }^{23}$ Upregulation of CD44 may also be a potential predictive and therapeutic target for breast cancer metastasis. ${ }^{16}$ It is noteworthy that sunitinib treatment of metastatic clear cell carcinoma induced CD44 expression in tumor tissues and high CD44 expression was associated with poor treatment outcome. ${ }^{83}$

Isoforms of CD44 predict clinical outcome. High CD44s expression was detected in the locally recurrent HCCs after local ablation therapy (LAT) compared to initial HCCs. In addition, high CD44s expression was associated with the intrahepatic dissemination of HCC after LAT. These observations suggested that high CD44s expression was an aggressive factor for recurrence after LAT for HCC. ${ }^{52}$ Similarly, CD44s expression was upregulated in high-grade human breast tumors. ${ }^{21}$ However, a contrary observation was also reported. Immunohistochemical analysis of 60 breast cancer tissues showed that CD44s negatively correlated with tumor diameter and tumor-node-metastasis TNM stage, but CD44v6 positively correlated with tumor diameter and tumor-node-metastasis stage. ${ }^{89}$ In addition, multivariate analysis demonstrated that high CD44v6 expression was an independent poor prognostic factor for disease-free survival and overall survival (OS) in colorectal cancer. ${ }^{54}$ Saito et al found that a high level of CD44v6 expression was inversely correlated with histological differentiation of the tumor in colon cancer cell line LoVo and HCT116 and it could independently predict a poor prognosis in disease-free survival and OS. ${ }^{54}$ Analysis of immunohistochemical staining for CD44v9 in 333 gastric cancer tissues found that the positive expression rates of CD44v9 in tumor were higher than those in nontumor tissues. Moreover, CD44v9 expression level correlated with progression. Pathological analyses indicated that intestinal subtype or well-differentiated gastric cancer showed higher CD44v9 in comparison with diffuse-type or poorly differentiated gastric cancer. Importantly, the strong positive expression in early gastric cancer indicated poor prognosis and appeared to be associated with lymph node metastasis. ${ }^{90}$
However, some studies found that $\mathrm{CD} 24^{+} / \mathrm{CD} 44^{-}$are indicator for poor prognosis in early invasive breast cancer, ${ }^{91}$ or CD44 predicts a better OS, which is opposite to most results of CD44. Generally speaking, CD44 is indicated to be a promising biomarker for diagnosis ${ }^{92}$ and prognosis. ${ }^{93,94}$

\section{Conclusion}

Above all, extensive studies of CD44 have provided new insights into the role of CD44 in cancer. CD44 plays an important role in cancer development, partly through regulating EMT and other pathways (Figure 3), and it could be a useful prognostic marker for various cancer types. However, opposite results were also reported ${ }^{88}$ It remains a challenge to determine which isoforms are more important in cancer development or which molecules associate with CD44. Specific antibody targeting to CD44 has acquired promising effect in some preclinical studies, but further analyses are still required before translation to clinic trial.

\section{Acknowledgments}

This work was supported by National Natural Science Foundation of China (grant numbers 81572608, 81172422, and 81072169 ). This work was also supported in part by R01CA132115-05A1 (RG Pestell).

\section{Disclosure}

The authors report no conflicts of interest in this work.

\section{References}

1. Spring FA, Dalchau R, Daniels GL, et al. The Ina and Inb blood group antigens are located on a glycoprotein of $80,000 \mathrm{MW}$ (the CDw44 glycoprotein) whose expression is influenced by the $\mathrm{In}(\mathrm{Lu})$ gene. Immunology. 1988;64(1):37-43.

2. Rodrigo JP, Dominguez F, Alvarez C, Gonzalez MV, Herrero A, Suarez C. Clinicopathologic significance of expression of CD44s and CD44v6 isoforms in squamous cell carcinoma of the supraglottic larynx. Am J Clin Pathol. 2002;118(1):67-72.

3. Erb U, Megaptche AP, Gu X, Buchler MW, Zoller M. CD44 standard and CD44v10 isoform expression on leukemia cells distinctly influences niche embedding of hematopoietic stem cells. J Hematol Oncol. 2014;7:29.

4. Misra S, Hascall VC, Markwald RR, Ghatak S. Interactions between hyaluronan and its receptors (CD44, RHAMM) regulate the activities of inflammation and cancer. Front Immunol. 2015;6:201.

5. Misra S, Heldin P, Hascall VC, et al. Hyaluronan-CD44 interactions as potential targets for cancer therapy. FEBS J. 2011;278(9):1429-1443.

6. Ponta H, Sherman L, Herrlich PA. CD44: from adhesion molecules to signalling regulators. Nat Rev Mol Cell Biol. 2003;4(1):33-45.

7. Turley EA, Noble PW, Bourguignon LY. Signaling properties of hyaluronan receptors. J Biol Chem. 2002;277(7):4589-4592.

8. Misra S, Hascall VC, De Giovanni C, Markwald RR, Ghatak S. Delivery of CD44shRNA/nanoparticles within cancer cells: perturbation of hyaluronan/CD44v6 interactions and reduction in adenoma growth in Apc Min/+ MICE. J Biol Chem. 2009;284(18):12432-12446. 
9. van der Windt GJ, Schouten M, Zeerleder S, Florquin S, van der Poll T. CD44 is protective during hyperoxia-induced lung injury. Am J Respir Cell Mol Biol. 2011;44(3):377-383.

10. Chanmee T, Ontong P, Kimata K, Itano N. Key roles of hyaluronan and its CD44 receptor in the stemness and survival of cancer stem cells. Front Oncol. 2015;5:180.

11. Naor D, Sionov RV, Ish-Shalom D. CD44: structure, function, and association with the malignant process. Adv Cancer Res. 1997;71:241-319.

12. Jang BI, Li Y, Graham DY, Cen P. The role of CD44 in the pathogenesis, diagnosis, and therapy of gastric cancer. Gut Liver. 2011;5(4):397-405.

13. Nagano O, Saya H. Mechanism and biological significance of CD44 cleavage. Cancer Sci. 2004;95(12):930-935.

14. Kwong LN, Dove WF. APC and its modifiers in colon cancer. Adv Exp Med Biol. 2009;656:85-106.

15. Wu K, Ning Z, Zeng J, et al. Silibinin inhibits beta-catenin/ZEB1 signaling and suppresses bladder cancer metastasis via dual-blocking epithelial-mesenchymal transition and stemness. Cell Signal. 2013; 25(12):2625-2633.

16. Uchino M, Kojima H, Wada K, et al. Nuclear beta-catenin and CD44 upregulation characterize invasive cell populations in non-aggressive MCF-7 breast cancer cells. BMC Cancer. 2010;10:414.

17. Yu G, Yao W, Xiao W, Li H, Xu H, Lang B. MicroRNA-34a functions as an anti-metastatic microRNA and suppresses angiogenesis in bladder cancer by directly targeting CD44. J Exp Clin Cancer Res. 2014; 33:779.

18. Xie G, Yao Q, Liu Y, et al. IL-6-induced epithelial-mesenchymal transition promotes the generation of breast cancer stem-like cells analogous to mammosphere cultures. Int J Oncol. 2012;40(4):1171-1179.

19. Ross JS, Sheehan CE, Williams SS, Malfetano JH, Szyfelbein WM, Kallakury BV. Decreased CD44 standard form expression correlates with prognostic variables in ovarian carcinomas. Am J Clin Pathol. 2001;116(1):122-128.

20. Leung EL, Fiscus RR, Tung JW, et al. Non-small cell lung cancer cells expressing CD44 are enriched for stem cell-like properties. PLoS One. 2010;5(11):e14062.

21. Brown RL, Reinke LM, Damerow MS, et al. CD44 splice isoform switching in human and mouse epithelium is essential for epithelial-mesenchymal transition and breast cancer progression. J Clin Invest. 2011; 121(3):1064-1074.

22. Shang Z, Cai Q, Zhang M, et al. A switch from CD44(+) cell to EMT cell drives the metastasis of prostate cancer. Oncotarget. 2015;6(2): $1202-1216$

23. Xu GF, Zhang WJ, Sun Q, Xu X, Zou X, Guan W. Combined epithelial-mesenchymal transition with cancer stem cell-like marker as predictors of recurrence after radical resection for gastric cancer. World J Surg Oncol. 2014;12:368.

24. Su YJ, Lai HM, Chang YW, Chen GY, Lee JL. Direct reprogramming of stem cell properties in colon cancer cells by CD44. EMBO J. 2011; 30(15):3186-3199.

25. Mahabir R, Tanino M, Elmansuri A, et al. Sustained elevation of Snail promotes glial-mesenchymal transition after irradiation in malignant glioma. Neuro Oncol. 2014;16(5):671-685.

26. Chung SS, Aroh C, Vadgama JV. Constitutive activation of STAT3 signaling regulates hTERT and promotes stem cell-like traits in human breast cancer cells. PLoS One. 2013;8(12):e83971.

27. Kinugasa H, Whelan KA, Tanaka K, et al. Mitochondrial SOD2 regulates epithelial-mesenchymal transition and cell populations defined by differential CD44 expression. Oncogene. 2015;34(41): 5229-5239.

28. Fernando J, Malfettone A, Cepeda EB, et al. A mesenchymal-like phenotype and expression of CD44 predict lack of apoptotic response to sorafenib in liver tumor cells. Int J Cancer. 2015;136(4):E161-E172.

29. Song Y, Li J, Zhu Y, et al. MicroRNA-9 promotes tumor metastasis via repressing E-cadherin in esophageal squamous cell carcinoma. Oncotarget. 2014;5(22):11669-11680.

30. Tian L, Li M, Ge J, et al. MiR-203 is downregulated in laryngeal squamous cell carcinoma and can suppress proliferation and induce apoptosis of tumours. Tumour Biol. 2014;35(6):5953-5963.
31. Wang PC, Weng CC, Hou YS, et al. Activation of VCAM-1 and its associated molecule CD44 leads to increased malignant potential of breast cancer cells. Int J Mol Sci. 2014;15(3):3560-3579.

32. Xing $\mathrm{P}, \mathrm{Li}$ JG, Jin F, et al. Fascin, an actin-bundling protein, promotes breast cancer progression in vitro. Cell Biochem Funct. 2011;29(4): 303-310.

33. Li L, Liu C, Amato RJ, Chang JT, Du G, Li W. CDKL2 promotes epithelial-mesenchymal transition and breast cancer progression. Oncotarget. 2014;5(21):10840-10853.

34. Li J, Zhou BP. Activation of beta-catenin and Akt pathways by Twist are critical for the maintenance of EMT associated cancer stem cell-like characters. BMC Cancer. 2011;11:49.

35. Yu M, Smolen GA, Zhang J, et al. A developmentally regulated inducer of EMT, LBX1, contributes to breast cancer progression. Genes Dev. 2009;23(15):1737-1742.

36. Mani SA, Guo W, Liao MJ, et al. The epithelial-mesenchymal transition generates cells with properties of stem cells. Cell. 2008;133(4): 704-715.

37. Fang X, Cai Y, Liu J, et al. Twist 2 contributes to breast cancer progression by promoting an epithelial-mesenchymal transition and cancer stem-like cell self-renewal. Oncogene. 2011;30(47):4707-4720.

38. Lee JK, Joo KM, Lee J, Yoon Y, Nam DH. Targeting the epithelial to mesenchymal transition in glioblastoma: the emerging role of MET signaling. Onco Targets Ther. 2014;7:1933-1944.

39. Zhang Z, Filho MS, Nor JE. The biology of head and neck cancer stem cells. Oral Oncol. 2012;48(1):1-9.

40. Way TD, Huang JT, Chou CH, Huang CH, Yang MH, Ho CT. Emodin represses TWIST1-induced epithelial-mesenchymal transitions in head and neck squamous cell carcinoma cells by inhibiting the beta-catenin and Akt pathways. Eur J Cancer. 2014;50(2):366-378.

41. Masui T, Ota I, Yook JI, et al. Snail-induced epithelial-mesenchymal transition promotes cancer stem cell-like phenotype in head and neck cancer cells. Int J Oncol. 2014;44(3):693-699.

42. Deep G, Jain AK, Ramteke A, et al. SNAI1 is critical for the aggressiveness of prostate cancer cells with low E-cadherin. Mol Cancer. 2014;13:37.

43. Marin-Aguilera M, Codony-Servat J, Reig O, et al. Epithelial-tomesenchymal transition mediates docetaxel resistance and high risk of relapse in prostate cancer. Mol Cancer Ther. 2014;13(5): 1270-1284.

44. Bhat-Nakshatri P, Appaiah H, Ballas C, et al. SLUG/SNAI2 and tumor necrosis factor generate breast cells with CD44+/CD24- phenotype. BMC Cancer. 2010;10:411.

45. Ju SY, Chiou SH, Su Y. Maintenance of the stemness in CD44(+) HCT-15 and HCT-116 human colon cancer cells requires miR-203 suppression. Stem Cell Res. 2014;12(1):86-100.

46. Cho SH, Park YS, Kim HJ, et al. CD44 enhances the epithelialmesenchymal transition in association with colon cancer invasion. Int J Oncol. 2012;41(1):211-218.

47. Yu D, Shin HS, Lee YS, Lee YC. miR-106b modulates cancer stem cell characteristics through TGF-beta/Smad signaling in CD44-positive gastric cancer cells. Lab Invest. 2014;94(12):1370-1381.

48. Wang L, Yang H, Abel EV, et al. ATDC induces an invasive switch in KRAS-induced pancreatic tumorigenesis. Genes Dev. 2015;29(2): 171-183.

49. Wang D, Zhu H, Liu Y, et al. The low chamber pancreatic cancer cells had stem-like characteristics in modified transwell system: is it a novel method to identify and enrich cancer stem-like cells? Biomed Res Int. 2014;2014:760303.

50. Jiang W, Zhang Y, Kane KT, et al. CD44 regulates pancreatic cancer invasion through MT1-MMP. Mol Cancer Res. 2015;13(1):9-15.

51. Nevo I, Woolard K, Cam M, et al. Identification of molecular pathways facilitating glioma cell invasion in situ. PLoS One. 2014;9(11): e111783.

52. Mima K, Hayashi H, Imai K, et al. High CD44s expression is associated with the EMT expression profile and intrahepatic dissemination of hepatocellular carcinoma after local ablation therapy. $J$ Hepatobiliary Pancreat Sci. 2013;20(4):429-434. 
53. Reinke LM, Xu Y, Cheng C. Snail represses the splicing regulator epithelial splicing regulatory protein 1 to promote epithelial-mesenchymal transition. J Biol Chem. 2012;287(43):36435-36442.

54. Saito S, Okabe H, Watanabe M, et al. CD44v6 expression is related to mesenchymal phenotype and poor prognosis in patients with colorectal cancer. Oncol Rep. 2013;29(4):1570-1578.

55. Geng S, Guo Y, Wang Q, Li L, Wang J. Cancer stem-like cells enriched with CD29 and CD44 markers exhibit molecular characteristics with epithelial-mesenchymal transition in squamous cell carcinoma Arch Dermatol Res. 2013;305(1):35-47.

56. Zhang Y, Wei J, Wang H, et al. Epithelial mesenchymal transition correlates with CD24+CD44+ and CD133+ cells in pancreatic cancer. Oncol Rep. 2012;27(5):1599-1605.

57. Liu S, Cong Y, Wang D, et al. Breast cancer stem cells transition between epithelial and mesenchymal states reflective of their normal counterparts. Stem Cell Rep. 2013;2(1):78-91.

58. Leontovich AA, Zhang S, Quatraro C, et al. Raf-1 oncogenic signaling is linked to activation of mesenchymal to epithelial transition pathway in metastatic breast cancer cells. Int J Oncol. 2012;40(6):1858-1864.

59. Arif K, Hussain I, Rea C, El-Sheemy M. The role of Nanog expression in tamoxifen-resistant breast cancer cells. Onco Targets Ther. 2015;8: 1327-1234.

60. Dalerba P, Dylla SJ, Park IK, et al. Phenotypic characterization of human colorectal cancer stem cells. Proc Natl Acad Sci U S A. 2007;104(24): 10158-10163.

61. Du L, Wang H, He L, et al. CD44 is of functional importance for colorectal cancer stem cells. Clin Cancer Res. 2008;14(21):6751-6760.

62. Santoyo-Ramos P, Likhatcheva M, Garcia-Zepeda EA, CastanedaPatlan MC, Robles-Flores M. Hypoxia-inducible factors modulate the stemness and malignancy of colon cancer cells by playing opposite roles in canonical Wnt signaling. PLoS One. 2014;9(11):e112580.

63. Masaki T, Goto A, Sugiyama M, et al. Possible contribution of CD44 variant 6 and nuclear beta-catenin expression to the formation of budding tumor cells in patients with T1 colorectal carcinoma. Cancer. 2001 92(10):2539-2546.

64. Lau WM, Teng E, Chong HS, et al. CD44v8-10 is a cancer-specific marker for gastric cancer stem cells. Cancer Res. 2014;74(9):2630-2641.

65. Wang D, Lu P, Zhang H, et al. Oct-4 and Nanog promote the epithelial-mesenchymal transition of breast cancer stem cells and are associated with poor prognosis in breast cancer patients. Oncotarget. 2014;5(21):10803-10815.

66. Creighton CJ, Li X, Landis M, et al. Residual breast cancers after conventional therapy display mesenchymal as well as tumor-initiating features. Proc Natl Acad Sci U S A. 2009;106(33):13820-13825.

67. Kondo S, Wakisaka N, Muramatsu M, et al. Epstein-Barr virus latent membrane protein 1 induces cancer stem/progenitor-like cells in nasopharyngeal epithelial cell lines. J Virol. 2011;85(21):11255-11264.

68. McFarlane S, McFarlane C, Montgomery N, Hill A, Waugh DJ. CD44-mediated activation of alpha5beta1-integrin, cortactin and paxillin signaling underpins adhesion of basal-like breast cancer cells to endothelium and Fibronectin-enriched matrices. Oncotarget. 2015;6(34):36762-36773.

69. Hanley WD, Burdick MM, Konstantopoulos K, Sackstein R. CD44 on LS174T colon carcinoma cells possesses E-selectin ligand activity. Cancer Res. 2005;65(13):5812-5817.

70. Shirure VS, Liu T, Delgadillo LF, et al. CD44 variant isoforms expressed by breast cancer cells are functional E-selectin ligands under flow conditions. Am J Physiol Cell Physiol. 2015;308(1):C68-C78.

71. McFarlane S, Coulter JA, Tibbits P, et al. CD44 increases the efficiency of distant metastasis of breast cancer. Oncotarget. 2015;6(13): 11465-11476.

72. Kim Y, Kumar S. CD44-mediated adhesion to hyaluronic acid contributes to mechanosensing and invasive motility. Mol Cancer Res. 2014; 12(10):1416-1429.
73. Perrot G, Langlois B, Devy J, et al. LRP-1 -CD44, a new cell surface complex regulating tumor cell adhesion. Mol Cell Biol. 2012;32(16):3293-3307.

74. Zhang C, Xu Y, Hao Q, et al. FOXP3 suppresses breast cancer metastasis through downregulation of CD44. Int J Cancer. 2015;137(6):1279-1290.

75. Paulis YW, Huijbers EJ, van der Schaft DW, et al. CD44 enhances tumor aggressiveness by promoting tumor cell plasticity. Oncotarget. 2015;6(23):19634-19646.

76. Fang XJ, Xu WL, Gong JL, Chen C, Fang LL, Chen QY. CD44 variant increases the invasive ability of human breast cancer cell line MCF-7 cells. Zhonghua Zhong Liu Za Zhi. 2010;32(1):22-28.

77. Herrera-Gayol A, Jothy S. CD44 modulates Hs578T human breast cancer cell adhesion, migration, and invasiveness. Exp Mol Pathol. 1999;66(1):99-108.

78. Nam K, Oh S, Lee KM, Yoo SA, Shin I. CD44 regulates cell proliferation, migration, and invasion via modulation of c-Src transcription in human breast cancer cells. Cell Signal. 2015;27(9):1882-1894.

79. Montgomery N, Hill A, McFarlane S, et al. CD44 enhances invasion of basal-like breast cancer cells by upregulating serine protease and collagen-degrading enzymatic expression and activity. Breast Cancer Res. 2012;14(3):R84.

80. Klarmann GJ, Hurt EM, Mathews LA, et al. Invasive prostate cancer cells are tumor initiating cells that have a stem cell-like genomic signature. Clin Exp Metastasis. 2009;26(5):433-446.

81. Gao Y, Foster R, Yang X, et al. Up-regulation of CD44 in the development of metastasis, recurrence and drug resistance of ovarian cancer. Oncotarget. 2015;6(11):9313-9326.

82. Martin-Villar E, Fernandez-Munoz B, Parsons M, et al. Podoplanin associates with CD44 to promote directional cell migration. Mol Biol Cell. 2010;21(24):4387-4399.

83. Mikami S, Mizuno R, Kosaka T, Saya H, Oya M, Okada Y. Expression of TNF-alpha and CD44 is implicated in poor prognosis, cancer cell invasion, metastasis and resistance to the sunitinib treatment in clear cell renal cell carcinomas. Int J Cancer. 2015;136(7):1504-1514.

84. Nicolini A, Ferrari P, Fini M, et al. Stem cells: their role in breast cancer development and resistance to treatment. Curr Pharm Biotechnol. 2011;12(2):196-205.

85. Wei X, Xu M, Wei Y, et al. The addition of rituximab to CHOP therapy alters the prognostic significance of CD44 expression. J Hematol Oncol. 2014;7:34

86. Ni J, Cozzi PJ, Hao JL, et al. CD44 variant 6 is associated with prostate cancer metastasis and chemo-/radioresistance. Prostate. 2014;74(6): 602-617.

87. Jin L, Hope KJ, Zhai Q, Smadja-Joffe F, Dick JE. Targeting of CD44 eradicates human acute myeloid leukemia stem cells. Nat Med. 2006; 12(10):1167-1174.

88. Dan T, Hewitt SM, Ohri N, et al. CD44 is prognostic for overall survival in the NCI randomized trial on breast conservation with 25 year follow-up. Breast Cancer Res Treat. 2014;143(1):11-18.

89. Wu XJ, Li XD, Zhang H, et al. Clinical significance of CD44s, CD44v3 and CD44v6 in breast cancer. J Int Med Res. 2015;43(2):173-179.

90. Go SI, Ko GH, Lee WS, et al. CD44 variant 9 serves as a poor prognostic marker in early gastric cancer, but not in advanced gastric cancer. Cancer Res Treat. Epub 2015 Mar 17.

91. Ahmed MA, Aleskandarany MA, Rakha EA, et al. A CD44(-)/CD24(+) phenotype is a poor prognostic marker in early invasive breast cancer. Breast Cancer Res Treat. 2012;133(3):979-995.

92. Basakran NS. CD44 as a potential diagnostic tumor marker. Saudi Med J. 2015;36(3):273-279.

93. Jiang L, Deng J, Zhu X, et al. CD44 rs13347 C $>$ T polymorphism predicts breast cancer risk and prognosis in Chinese populations. Breast Cancer Res. 2012;14(4):R105.

94. Lu X, Xu K, Lu H, et al. CD44(+)/CD24(-) cells are transit progenitors and do not determine the molecular subtypes and clinical parameters in breast carcinomas. Ultrastruct Pathol. 2011;35(2):72-78. 


\section{Publish your work in this journal}

OncoTargets and Therapy is an international, peer-reviewed, open access journal focusing on the pathological basis of all cancers, potential targets for therapy and treatment protocols employed to improve the management of cancer patients. The journal also focuses on the impact of management programs and new therapeutic agents and protocols on

patient perspectives such as quality of life, adherence and satisfaction. The manuscript management system is completely online and includes a very quick and fair peer-review system, which is all easy to use. Visit http://www.dovepress.com/testimonials.php to read real quotes from published authors.

Submit your manuscript here: http://www.dovepress.com/oncotargets-and-therapy-journal 